\title{
UN atlas links climate change to disease spread
}

A sserting that they've uncovered new evidence of the links between climate change and diseases such as diarrhea, malaria, dengue fever and meningitis, the United Nations' agencies for health and meteorology have unveiled an Atlas of Health and Climate.

The atlas "provides sound scientific information on the connections between weather and climate and major health challenges. These range from diseases of poverty to emergencies arising from extreme weather events and disease outbreaks. They also include environmental degradation, the increasing prevalence of noncommunicable diseases and the universal trend of demographic ageing," World Health Organization (WHO) Director General Dr. Margaret Chan and World Meteorological Organization (WMO) Secretary-General Michel Jarraud stated in their preface to the new atlas (www.who.int/iris/bitstream/10665 /76224/5/9789241564526_eng.pdf).

"The Atlas conveys three key messages," the pair added. "First, climate affects the geographical and temporal distribution of large burdens of disease and poses important threats to health security, on time scales from hours to centuries. Second, the relationship between health and climate is influenced by many other types of vulnerability, including the physiology and behaviour of individuals, the environmental and socio-economic conditions of populations, and the coverage and effectiveness of health programmes. Third, climate information is now being used to protect health through risk reduction, preparedness and response over various spatial and temporal scales and in both affluent and developing countries."

The atlas is intended as a tool for policy-makers and health care providers in the development of solutions to climatic hazards, administrators say.

It was the product of a unique, collaboration between the WHO and WMO that has opened up a new approach to combating preventable diseases related

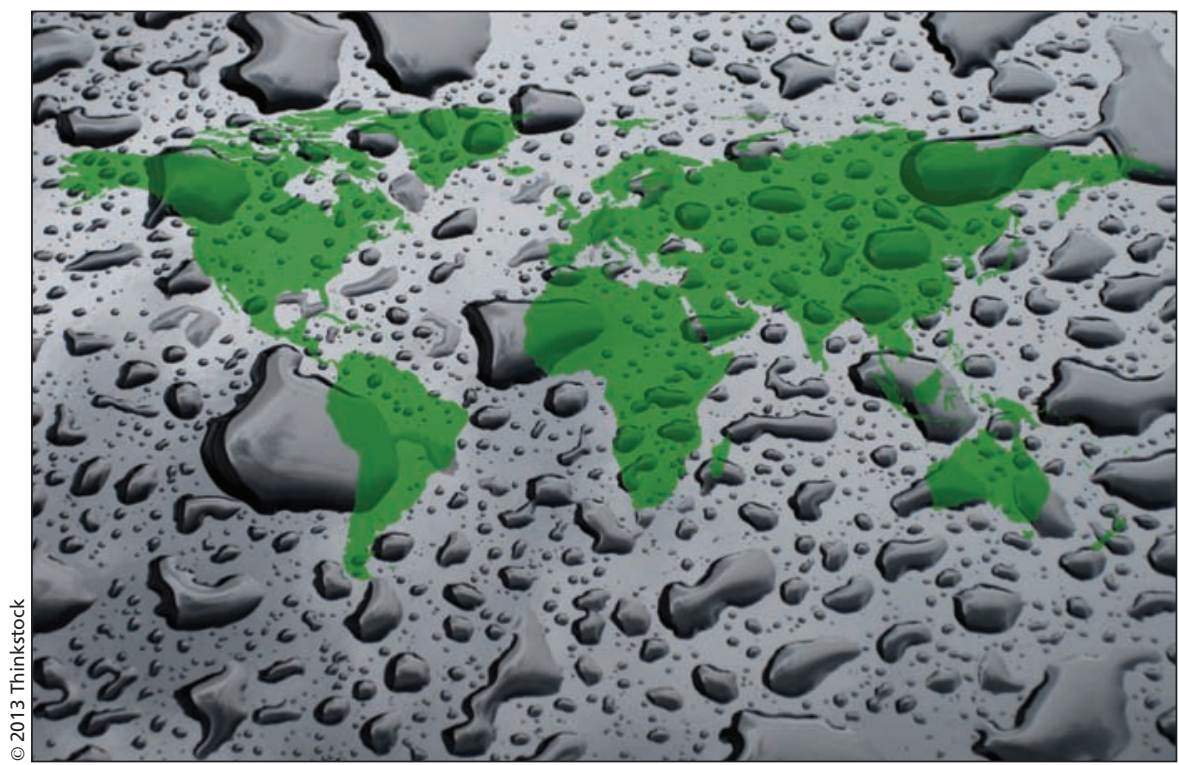

The World Health Organization and World Metereological Organization say they've opened up a new approach to combatting preventable diseases related to climatic conditions.

to climatic conditions, says Dr. Geoff Love, director of weather and disaster risk reduction services at WMO. "We understand a lot more about the climate system than we did probably even 10 years ago. We've started to reach the point where there are viable climate services that we can provide to specialized sectors and one of those sectors is the public health area."

"There are a number of health issues which are exacerbated or eased by climatic conditions, weather conditions, and what we're trying to do is build an understanding of those linkages and build an awareness," Love adds.

Ultimately, such information should help decision-makers in health epidemic prevention, particularly in developing countries in which climate-related diseases are endemic, Love says.

The atlas also touches on emerging environmental challenges - such as rising temperatures and ultraviolet radiation, pollen and air pollution levels that could lead to health complications in developing nations, he adds. "There's a whole host of areas where there are opportunities to do better and we have the climatological and meteorological knowledge to say that for events coming up, here are the things you have to do. And the process now is to get the public health systems comfortable and trusting of the services and build the relationship between the meteorological community and the health community so that those things happen."

The next step will be to organize climate and health datasets into a monthly or weekly updating process to track the time scale of decision-making processes, Love says.

Love adds that the atlas also represented a rare opportunity for collaboration between the two UN agencies. "The two organizations are only about a kilometer apart in Geneva, (Switzerland) but generally the meteorological world and the health world don't cross. ... It really is unashamedly an advocacy document and it's just saying here are the areas where we know from ongoing research that there are opportunities to turn this into services that people can use to improve decisionmaking on the ground in a whole variety of areas." - Adam Miller, CMAJ

CMAJ 2013. DOI:10.1503/cmaj.109-4340 